\title{
VARIABILIDADE GENÉTICA EM POPULAÇÕES DE PITANGUEIRA ORIUNDAS DE AUTOPOLINIZAÇÃO E POLINIZAÇÃO LIVRE, ACESSADA POR AFLP ${ }^{1}$
}

\author{
RODRIGO CEZAR FRANZON², CAROLINE MARQUES CASTRO ${ }^{3}$, \\ MARIA DO CARMO BASSOLS RASEIRA ${ }^{3}$
}

RESUMO- Foram utilizados marcadores AFLP para a avaliação de populações de plantas de pitangueira (Eugenia uniflora) oriundas de autopolinização e de polinização livre, com o objetivo de verificar a variabilidade existente entre e dentro dessas populações, visando a fornecer mais informações que ajudem no entendimento do modo de reprodução dessa espécie. O material vegetal utilizado foi oriundo de duas seleções de pitangueira ("Pit 15" e "Pit 52"), mantidas na Embrapa Clima Temperado. De cada seleção, foram obtidas duas populações F1, por meio de autopolinização e de polinização livre, totalizando quatro populações. Foram analisados 18 indivíduos de cada população e as duas plantas-mãe, totalizando 74 indivíduos. Foram utilizadas três combinações de primers AFLP e calculada a similaridade genética entre plantas pelo coeficiente de Jaccard. Uma estimativa da variabilidade genética entre e dentro das populações foi estimada pela AMOVA. As três combinações de primers AFLP utilizadas amplificaram um total de 178 locos AFLP, dos quais 114 (64,0\%) foram polimórficos entre todos os indivíduos. Não houve separação clara entre populações descendentes da mesma planta-mãe. Foi observado maior polimorfismo de marcadores AFLP em populações de polinização livre. A proporção da variabilidade genética total entre populações foi significativa, embora tenha sido menor do que aquela observada dentro das populações. A reprodução da pitangueira é decorrente tanto da autofertilização quanto da polinização cruzada, sendo necessário, no entanto, novos estudos para determinar qual a estratégia de reprodução mais eficiente.

Termos para Indexação: Eugenia uniflora, Myrtaceae, biologia reprodutiva, similaridade genética.

\section{GENETIC VARIABILITY IN SURINAM CHERRY POPULATIONS ORIGINATED FROM SELF-POLLINATION AND CROSS POLLINATION, ESTIMATED BY AFLP}

\begin{abstract}
AFLP molecular markers were used aiming to study the genetic variability within and between Surinam cherry (Eugenia uniflora) populations, originated from self-pollination and open pollination of two selections (Pit 15 and Pit 52) of the Embrapa Clima Temperado collection. The objective was to achieve a better understanding about the reproduction way of this species. Two progenies were obtained from each selection being one from self-pollination and another from open-pollination, resulting in four populations. The analysis was carried out in 18 individuals of each progeny and the two mother plants, totalizing 74 genotypes. Three AFLP primer combinations were used and the genetic similarity was calculated by Jaccard coefficient. Genetic variability within and between populations was estimated by AMOVA. The three primer combinations amplified 178 loci, of which 114 (64\%) were polymorphic, considering all the genotypes. There was not a clear separation between the two progenies of the same mother plant. Larger polymorphism of AFLP markers was observed in the open-pollinated populations. The proportion of total genetic variability was significant, between populations from open-pollination, although smaller than the variability observed within populations. The Surinam cherry reproduction is based on both self-fertilization as well as cross-pollination. Nevertheless it is rather important to do further studies in order to determine which reproduction mode is the most efficient.
\end{abstract}

Index terms: Eugenia uniflora, Myrtaceae, reproductive biology, genetic similarity.

\footnotetext{
${ }^{1}$ (Trabalho 034-09). Recebido em: 27-01-2009. Aceito para publicação em: 01-06-2009.

${ }^{2}$ Dr., Embrapa Cerrados, BR 020, Km 18, Caixa Postal 8223, Planaltina-DF. CEP: 73310-970. E-mail: rodrigo.franzon@cpac.embrapa.br ${ }_{3}^{3}$ Dr., Embrapa Clima Temperado, Rodovia BR 392, km 78, Pelotas-RS. CEP: 96001-970. E-mail: caroline@cpact.embrapa.br, bassols@cpact.embrapa.br*(*Bolsista PQ/CNPq).
} 


\section{INTRODUÇÃO}

A pitangueira (Eugenia uniflora L.) é uma fruteira nativa do Brasil e apresenta quatro diferentes centros de diversidade: Nordeste-Caatinga, SulSudeste, Brasil Central-Cerrado e Mata Atlântica (Donadio et al., 2002). Esta Mirtácea tem potencial para ser cultivada comercialmente, e seus frutos podem ser utilizados na alimentação humana, tanto para consumo in natura quanto para o processamento.

O conhecimento sobre a polinização, a reprodução e a variabilidade entre populações são ainda raros para esta espécie. Informações desta natureza são importantes para o manejo, principalmente quando se pensa na introdução da espécie em cultivos comerciais, bem como para trabalhos de melhoramento genético e de preservação. Uma alternativa para avaliar a variabilidade em populações é a caracterização morfológica, fenológica e agronômica dos indivíduos. Entretanto, a caracterização de genótipos, bem como o estudo da variabilidade com base nestes caracteres, apresenta uma série de limitações, tais como: a demora na avaliação; não pode ser realizada em qualquer período do ano; em plantas frutíferas muitas avaliações somente são possíveis de serem realizadas quando estas entram em produção, requerendo, assim, um custo elevado e tempo prolongado para análise; acessar pequena porção do genoma da planta; os marcadores morfológicos existem em número limitado, além de ser dependente e influenciada pelo ambiente (Dettori \& Palombi, 2000; Salla et al., 2002; Bianchi et al., 2003; Yamagishi et al., 2005). Além disso, essas avaliações são feitas de forma subjetiva, e o resultado pode variar de acordo com a percepção dos avaliadores.

Como alternativa a esses inconvenientes, podem-se utilizar marcadores moleculares, que revelam polimorfismo de sequências de DNA, e têm sido de grande importância para acessar a variabilidade genética dentro do pool gênico de espécies cultivadas, bem como na análise da diversidade e caracterização de germoplasma (Salla et al., 2002; Ferreira et al., 2007). Os marcadores de DNA têm sido usados em diferentes fruteiras e outras espécies perenes para identificação varietal, avaliar similaridade e relação genética entre genótipos, monitorar variabilidade genética, construir mapas genéticos e encontrar marcadores para características de interesse agronômico (Mehlenbacher, 1995; Pigato \& Lopes, 2001; Salla et al., 2002; Upadhyay et al., 2004).

O estudo da variabilidade genética em pitangueira, por meio de características fenotípicas, demanda longo período de tempo, por se tratar de uma espécie perene. $\mathrm{O}$ uso de marcadores moleculares na avaliação da variabilidade genética permite caracterizar indivíduos, de qualquer espécie, de maneira precoce e em menor espaço de tempo (Viana et al., 2003), tornando-se, portanto, altamente viável.

Análises AFLP (Amplified fragment length polymorphism) têm sido usadas para descrever a estrutura da população e polimorfismo genético de diversas espécies vegetais produtoras de grãos (Margis et al., 2002). Em fruteiras, tem sido utilizada em análises com pessegueiro (Aradhya et al., 2004), várias espécies de Citrus (Bretó et al., 2001), em videira (Cervera et al., 1998) e em ameixeira-japonesa (Vieira et al., 2005), dentre outros.

Em pitangueira, a técnica AFLP foi utilizada para analisar o nível de variabilidade genética entre populações no Rio de Janeiro (Margis et al., 2002). Salgueiro et al. (2004), com o objetivo de estabelecer associação entre os diferentes fatores que influenciam na distribuição da variabilidade genética entre populações desta espécie, distribuídas ao longo do litoral brasileiro, utilizaram esta mesma técnica, associada com SSRs (microssatélites) e RFLPs (Restriction fragment length polymorphisms).

Em relação ao modo de reprodução desta espécie, Silva (2006) classifica a espécie como parcialmente autocompatível, com índice de autocompatibilidade igual a 0,62 , sendo consideradas autocompatíveis espécies com índice acima de 0,75 (Lloyd \& Schoen, 1992). Já, Franzon (2008) classifica a espécie como autocompatível, mas que necessita da atuação de agentes polinizadores, principalmente abelhas melíferas, para melhor frutificação.

No presente trabalho, foram utilizados marcadores AFLP para a avaliação de populações de plantas de pitangueira oriundas de autopolinização e de polinização livre, com o objetivo de verificar a variabilidade existente entre e dentro destas populações, visando a fornecer mais informações que ajudem no entendimento do modo de reprodução desta espécie.

\section{MATERIAL E MÉTODOS}

Os trabalhos foram desenvolvidos no Laboratório de Biologia Molecular da Embrapa Clima Temperado, em Pelotas-RS. O material vegetal utilizado foi oriundo de duas seleções de pitangueira ("Pit 15" e "Pit 52"), mantidas no Banco Ativo de Germoplasma (BAG) de Fruteiras Nativas do Sul do Brasil, nesta Unidade da Embrapa. Atualmente, existem cerca de 150 seleções de pitangueira no BAG, plantadas em espaçamento de $5 \mathrm{~m}$ entre filas e 2 m entre plantas. A planta "Pit 15" foi selecionada a partir de seedlings obtidos de sementes coletadas 
de uma única planta em propriedade particular, no interior do município de Pelotas-RS. Já, a planta "Pit 52" foi selecionada em um segundo ciclo, em população formada por seedlings obtidos a partir de sementes coletadas na população anteriormente introduzida.

De cada uma das duas seleções, foram obtidas duas populações, entre fevereiro e março de 2006, por meio de autopolinização e de polinização livre, totalizando quatro populações. Para a obtenção das populações de autopolinização, foram ensacados ramos com botões florais e, no dia da antese, as flores foram polinizadas manualmente com pólen da mesma flor. Quando maduros, os frutos foram colhidos, e as sementes colocadas para germinar, em casa de vegetação. Para a população de polinização livre, frutos foram colhidos ao acaso, na mesma época de colheita dos frutos de autopolinização.

As plantas foram divididas em dois grupos: um grupo formado pela seleção "Pit 52" e suas progênies, doravante denominada Gp52a (oriunda de autopolinização), e Gp52L (derivada de polinização livre), e outro grupo formado pela seleção "Pit 15" e suas progênies, doravante denominado Gp15a (oriunda de autopolinização), e Gp15L (derivada de polinização livre).

Na extração do DNA, realizada de acordo com o protocolo proposto por Doyle \& Doyle (1987), utilizou-se entre $0,15 \mathrm{~g}$ e $0,20 \mathrm{~g}$ de tecido vegetal, coletado de folhas jovens completamente expandidas, de 18 indivíduos de cada uma das quatro populações, e das duas plantas-mãe, totalizando 74 indivíduos. Os 18 indivíduos foram escolhidos ao acaso em cada uma das populações obtidas. Para extração de DNA das plantas-mãe, folhas jovens foram coletadas a campo. A quantificação do DNA foi realizada em gel de agarose a $1 \%$, corado com brometo de etídeo, e revelado sob luz ultravioleta. As amostras de DNA foram diluídas para uma concentração final de 10 ng. $\mu \mathrm{L}^{-1}$, em $\mathrm{H}_{2} \mathrm{O}$ MilliQ ${ }^{\circledR}$ autoclavada.

Na reação de digestão, para cada amostra, foram utilizados $10 \mu \mathrm{L}$ de DNA $\left(10 \mathrm{ng} . \mu \mathrm{L}^{-1}\right) ; 2 \mu \mathrm{L}$ de enzimas EcoRI/MseI (1,25 U. $\left.\mu \mathrm{L}^{-1}\right) ; 5 \mu \mathrm{L}$ Tampão 5x [Tris- $\mathrm{HCl}(\mathrm{pH}$ 7,5) $10 \mathrm{mM}$, Acetato $\mathrm{Mg} 10 \mathrm{mM}$, Acetato $\mathrm{K} 50 \mathrm{mM}$ ], ambos fornecidos pela Invitrogen; e $8 \mu \mathrm{L}$ de $\mathrm{H}_{2} \mathrm{O}$ MilliQ ${ }^{\circledR}$, num volume final de reação de $25 \mu \mathrm{L}$. A reação foi incubada por $3 \mathrm{~h}$ a $37^{\circ} \mathrm{C}$, seguido por um período de $15 \mathrm{~min}$ a $70{ }^{\circ} \mathrm{C}$.

Os fragmentos resultantes da digestão foram ligados aos adaptadores específicos para os locais de restrição EcoRI e MseI. Nesta etapa, utilizaram-se $10 \mu \mathrm{L}$ do DNA digerido, sendo adicionados 9,6 $\mu \mathrm{L}$ de solução de ligação de adaptadores, do Kit $A F L P^{\circledR}$ Analysis System I (Invitrogen), e 0,4 $\mu \mathrm{L}$ da enzima
T4 DNA ligase (Invitrogen). O material foi incubado por duas horas a $20^{\circ} \mathrm{C}$.

As reações de pré-amplificação foram desenvolvidas em um volume final de $10 \mu \mathrm{L}$, sendo composta por $1 \mu \mathrm{L}$ da solução resultante da ligação dos adaptadores, diluída 1:10, em $\mathrm{H}_{2} \mathrm{O}$ MilliQ ${ }^{\circledR}$ autoclavada; $1 \mu \mathrm{L}$ do 10X PCR Buffer [Tris- $\mathrm{HCl} \mathrm{pH} 8,4$ (20 mM), $\mathrm{KCl}(50 \mathrm{mM})$ ]; $0,5 \mu \mathrm{L}$ de $\mathrm{MgCl}_{2}$ (50 mM), ambos da Invitrogen; $0,8 \mu \mathrm{L}$ de dNTP mix $(2,5 \mathrm{mM}$ de cada); $0,2 \mu \mathrm{L}$ de Taq DNA polimerase $\left(5 \mathrm{U} . \mu \mathrm{L}^{-1}\right)$; $0,3 \mu \mathrm{L}$ do primer EcoRI+1 (50 ng. $\left.\mu \mathrm{L}^{-1}\right)$; e $0,3 \mu \mathrm{L}$ do primer MseI+1 (50 ng. $\left.\mu \mathrm{L}^{-1}\right)$, completando o volume com 5,9 $\mu \mathrm{L}$ de $\mathrm{H}_{2} \mathrm{O}$ MilliQ ${ }^{\circledR}$. O programa de PCR utilizado seguiu o protocolo sugerido por Vos et al. (1995), num total de 20 ciclos, sendo cada ciclo composto por $30 \mathrm{~s} \mathrm{a} 94^{\circ} \mathrm{C}, 1 \mathrm{~min}$ a $56^{\circ} \mathrm{C}$, e $1 \mathrm{~min}$ a $72{ }^{\circ} \mathrm{C}$. O produto da reação de pré-amplificação foi diluído, em $\mathrm{H}_{2} \mathrm{O}$ MilliQ ${ }^{\circledR}$ autoclavada, na proporção $1: 10$, para então ser submetido à amplificação seletiva.

Na amplificação final seletiva, cada reação foi realizada em um volume final de $10 \mu \mathrm{L}$, contendo: 2,5 $\mu \mathrm{L}$ da solução de DNA pré-amplificado diluída $1: 10 ; 1 \mu \mathrm{L}$ de solução PCR buffer $10 \mathrm{X}$ [Tris- $\mathrm{HCl}$ pH 8,4 (20 mM), $\mathrm{KCl}(50 \mathrm{mM})] ; 0,4 \mu \mathrm{L}$ de $\mathrm{MgCl}_{2}$ (50 mM); 1,6 $\mu \mathrm{L}$ de dNTP mix $(2,5 \mathrm{mM}) ; 0,3 \mu \mathrm{L}$ BSA $\left(10 \mathrm{mg} . \mu \mathrm{L}^{-1}\right) ; 0,2 \mu \mathrm{L}$ de Taq DNA polymerase (5 U. $\left.\mu \mathrm{L}^{-1}\right) ; 1,7 \mu \mathrm{L}$ de $\mathrm{H}_{2} \mathrm{O}$ MilliQ ${ }^{\circledR}$ autoclavada; $2 \mu \mathrm{L}$ do primer EcoRI+3 (50 ng. $\left.\mu \mathrm{L}^{-1}\right)$ e $0,3 \mu \mathrm{L}$ do primer MseI+3 (50 ng. $\left.\mu \mathrm{L}^{-1}\right)$. O programa de PCR utilizado seguiu o protocolo proposto por Vos et al., (1995): desnaturação a $94{ }^{\circ} \mathrm{C}$ por $10 \mathrm{~s}$, seguido de anelamento a $65^{\circ} \mathrm{C}$ por $30 \mathrm{~s}$, e extensão a $72^{\circ} \mathrm{C}$ por $1 \mathrm{~min}$, repetido por 13 ciclos, sendo que, em cada ciclo, a temperatura de anelamento foi reduzida em $0,7^{\circ} \mathrm{C}$ até atingir $56^{\circ} \mathrm{C} ; 23$ ciclos a $94{ }^{\circ} \mathrm{C}$ por $10 \mathrm{~s}$, $56{ }^{\circ} \mathrm{C}$ por $30 \mathrm{~s}$, e $72{ }^{\circ} \mathrm{C}$ por $1 \mathrm{~min}$. Foram utilizadas três combinações de primers: (P1) EcoRI +ACA / MseI +CTT; (P2) EcoRI +AGC / MseI +CTT; e (P3) $\mathrm{EcoRI}+\mathrm{AAC} / \mathrm{Mse} \mathrm{I}+\mathrm{CAG}$.

Todas as etapas das reações foram realizadas em termociclador GeneAmp PCR System 9700 (Applied Biosystems, Foster City, CA, USA). Ao produto da reação de amplificação final $(10 \mu \mathrm{L})$, foram adicionados $4 \mu \mathrm{L}$ da solução tampão de carregamento (formamida deionizada 99\%, EDTA $10 \mathrm{mM}, 0,025 \%$ de xileno-ciano e $0,025 \%$ de azul de bromofenol) e procedida a desnaturação das amostras a $94{ }^{\circ} \mathrm{C}$ por $5 \mathrm{~min}$. Foram aplicados 6 $\mu \mathrm{L}$ desta solução em gel de sequenciamento (poliacrilamida $6 \% \mathrm{p} / \mathrm{v}$, ureia $7 \mathrm{M}$ ), sendo utilizada cuba para eletroforese Bio-Rad (modelo Sequi Gen GT) com fonte Bio-Rad (modelo PowerPac 3000).

Os fragmentos amplificados foram visualiza- 
dos utilizando o protocolo de coloração com nitrato de prata (Creste et al., 2001). O tamanho dos alelos foi estimado em comparação visual com o marcador de peso molecular de DNA de $25 \mathrm{pb}$ (InvitroGen Life Technologies, Carlsbad, Calif., USA).

Os dados de presença (1) e ausência (0) de marcadores obtidos na análise de AFLP dos 74 indivíduos estudados permitiram o cálculo da similaridade genética $\left(\mathrm{S}_{\mathrm{ij}}\right)$ entre todos os pares de genótipos, através do coeficiente de Jaccard. Para análise, foram eliminados os marcadores que foram monomórficos para todos os 74 indivíduos. Com base na matriz de similaridade gerada foi construído um dendrograma pelo método de agrupamento da distância média (UPGMA - Unweighted Pair-Group Method of Arithmetic Averages). O ajuste entre a matriz de similaridade e o dendrograma foi estimado pelo coeficiente de correlação cofenética - r (Sokal \& Rohlf, 1962). Todas as análises descritas acima foram realizadas por meio do programa computacional NTSYS pc 2.1 (Rohlf, 2000).

A partir da matriz original gerada, a variabilidade genética entre e dentro das populações foi estimada pela análise da variância molecular (AMOVA), usando o programa GENES (versão 2007.0.0.). A AMOVA calcula o valor $\mathrm{F}_{\mathrm{st}}$, que equivale à proporção da variação genética total fracionada entre populações (Excoffier et al., 1992).

\section{RESULTADOS E DISCUSSÃO}

As três combinações de primers AFLP utilizadas amplificaram um total de 178 locos AFLP, dos quais $114(64,0 \%)$ foram polimórficos entre todos os indivíduos (Tabela 1). O número total de locos amplificados para cada par de primers variou entre 49 e 65 , com polimorfismo variando entre $47,7 \%$ e $75,5 \%$. Todos os locos analisados apresentaram peso molecular entre 100 e $500 \mathrm{pb}$.

A percentagem de locos polimórficos nas populações de polinização livre foi ligeiramente maior do que nas populações de autopolinização (Tabela 2). De certo modo, isto era esperado, pois a autopolinização, em qualquer espécie, provoca endogamia. Porém, as pequenas diferenças observadas entre as populações de autopolinização e de polinização livre (11,1\% no Gp52, e 5,9\% no Gp15 - Tabela 2) estão aquém do esperado, pois nesta última o esperado era que ocorresse maior polimorfismo, por ser a pitangueira uma espécie polinizada principalmente por abelhas (Silva \& Pinheiro, 2007). Isso pode estar ocorrendo devido a um elevado grau de parentesco entre plantas do BAG de pitangueira da Embrapa Clima Temperado, o que também explicaria o me- nor grau de polimorfismo encontrado em relação a outros trabalhos com esta mesma espécie (Margis et al., 2002; Salgueiro et al., 2004). Os primeiros autores obtiveram $91,4 \%$ de locos polimórficos na avaliação de três populações desta espécie no Rio de Janeiro, com uma distância entre elas não superior a $30 \mathrm{~km}$. Por sua vez, Salgueiro et al. (2004) obtiveram $78,05 \%$ de locos polimórficos, analisando cinco populações de pitangueira de diferentes regiões (Rio de Janeiro, Pernambuco e Rio Grande do Sul). Outra possibilidade para a ocorrência de baixa variabilidade entre plantas, nas populações F1 de polinização livre, seria a ocorrência de autofertilização na pitangueira, o que também contribuiria para diminuir os níveis de polimorfismo.

Os índices de similaridade obtidos reforçam estas duas possibilidades, elevado grau de parentesco entre plantas e autofertilização. Embora a análise de agrupamento (Figura 1) tenha separado claramente os indivíduos em dois grupos distintos (Gp52 e Gp15), dentro de cada grupo não ocorre uma separação clara entre populações, inclusive com plantas de polinização livre no GP52 (por exemplo: L_15 e L_12) sendo observadas mais próximas da planta-mãe (Pit 52) do que algumas plantas de autopolinização. A similaridade entre os dois grupos foi de aproximadamente $48 \%$, com um coeficiente de correlação cofenética (r) de 0,96 , o que evidencia bom ajuste entre a representação gráfica das distâncias no dendrograma e a sua matriz original. A partir da matriz de similaridade, foi obtida a similaridade média entre todos os indivíduos analisados, que ficou em 60,4\%.

A partir da matriz de similaridade também foram obtidos os índices de similaridade média para cada grupo (Gp52 e Gp15) e para cada população dentro do grupo. A similaridade média geral entre todos os indivíduos pertencentes ao Gp52 foi 75,1\%, enquanto para o Gp15 foi 71,6\%. Entre plantas autopolinizadas, a similaridade média no Gp52a foi 78,9\%, e no Gp15a foi $73,7 \%$. Já, entre plantas de polinização livre, foi 75,3\% no Gp52L e 69,0\% no Gp15L.

Os resultados da análise da variância molecular - AMOVA (Tabela 3), mostram que a maior variação está presente dentro das populações de pitangueira avaliadas. Porém, os valores de variação encontrados entre populações, embora baixos, foram altamente significativos. No grupo $\mathrm{Gp} 52$, o $\mathrm{F}_{\text {st }}$ estimado $\left(\mathrm{F}_{\mathrm{st}}=0,1336\right)$ indica que $86,64 \%$ da variação total está presente dentro das populações e $13,36 \%$ entre elas. No grupo Gp15, o $\mathrm{F}_{\mathrm{st}}$ estimado $\left(\mathrm{F}_{\mathrm{st} \mathrm{Gp} 15}=0,061\right)$ indica que $93,9 \%$ da variação está presente dentro das populações e apenas $6,1 \%$ entre elas. Maior variação dentro de populações desta espécie também foi observada em trabalhos anteriores (Margis et al., 2002; 
Salgueiro et al., 2004). De acordo com Ouborg et al. (1999), uma variação significante entre populações pode indicar restrito fluxo de genes.

No presente trabalho, esse resultado era esperado, pois, dentro de cada grupo (Gp52 e Gp15), as populações analisadas têm a mesma origem materna, o que reduz a diferença entre elas. No entanto, no trabalho de Salgueiro et al. (2004), a variabilidade observada dentro de populações $(78,9 \%)$ foi maior do que o esperado, uma vez que as populações analisadas estavam a uma distância de, pelo menos, $99 \mathrm{~km}$ uma da outra e não existia interação entre elas. Os autores atribuem essa variabilidade a interações (fluxo gênico) ocorridas no passado. Margis et al. (2002), por sua vez, observaram $88 \%$ da variabilidade dentro das populações e sugerem que ocorra um intenso fluxo de genes entre elas, uma vez que se encontram a uma distância não superior a $30 \mathrm{~km}$ uma da outra. Porém, estes mesmos autores destacam que o grau de diferenciação populacional observado foi maior do que o esperado para uma espécie com pequenas distâncias entre populações e sugerem que as mesmas estariam sendo influenciadas por diferentes graus de impacto humano, por meio da fragmentação da mata, o que estaria reduzindo o número de indivíduos ou, ainda, obstruindo o fluxo contínuo de pólen e sementes. Em trabalho de revisão de literatura, Wang et al. (2007) destacam que a diferenciação genética entre populações é função do fluxo de genes entre elas, principalmente via dispersão de pólen e sementes.

Os valores $\mathrm{F}_{\text {st }}$ observados no presente trabalho foram $\mathrm{F}_{\text {st }}=0,1336$, para o $\mathrm{Gp} \mathrm{52,} \mathrm{e} \mathrm{F}_{\text {st }}=0,061$, para o Gp 15. Valores de $\mathrm{F}_{\text {st }}$ entre 0,05 e 0,15 sugerem moderada diferenciação genética entre populações (Wright, 1978, citado por Mwase et al., 2006). Neste trabalho, ambos os valores $\mathrm{F}_{\mathrm{st}}$ estão dentro desta faixa. No entanto, pode-se inferir que esta diferenciação, entre populações de autopolinização e polinização livre dentro de cada grupo, só não foi mais acentuada devido à ocorrência de autofertilização ou, ainda, polinização com pólen de indivíduos muito próximos geneticamente (aparentados), nas plantas de polinização livre. Isso é corroborado pelo dendrograma, onde as populações dentro dos grupos são próximas, não havendo separação clara entre elas, conforme já discutido. Outras possíveis causas desta baixa variabilidade são o pequeno tamanho de população utilizado $(\mathrm{N}=18)$ e o fato de apenas três combinações de primers terem sido utilizadas.

Os resultados obtidos por Salgueiro et al. (2004) indicam considerável diferenciação entre as cinco populações de pitangueira avaliadas $\left(\mathrm{F}_{\mathrm{st}}=\right.$ 0,211). Levando-se em consideração o elevado índice de fragmentação que as matas nativas vêm sofrendo nas diferentes regiões do País, pode-se concluir que populações desta espécie, ao ficarem isoladas uma da outra, diferenciam-se ao longo do tempo, pelo aumento da frequência de alelos raros em diferentes populações. No presente estudo, quando se comparam as populações em pares (Tabela 4), a AMOVA mostra que a maior parte da variação está entre as populações. Analisando as duas populações oriundas de autopolinização, o valor $\mathrm{F}_{\text {st }}$ estimado $(0,6293)$ indica que a percentagem da variação total residente entre as populações é $62,93 \%$.

Quando se comparam as duas populações oriundas de polinização livre, $\mathrm{o}_{\mathrm{st}}=0,5352$ indica que também ocorre grande diferenciação genética entre elas, o que não seria o esperado em populações oriundas de acasalamento ao acaso, considerando a ocorrência de polinização cruzada. Entretanto, muito pouco se conhece sobre o modo de reprodução da pitangueira, incluindo modo de polinização, bem como dispersão de pólen e sementes. A falta de informações desta natureza não é exclusividade desta espécie, e também é relatada por Proença \& Gibbs (1994) para outras espécies de Myrtaceae que ocorrem no Brasil. Além disso, sabe-se que, para outras espécies desta família nativas no Sul do Brasil, tais como uvalheira (E. pyriformis), cerejeira-do-mato (E. involucrata), guabirobeira (Campomanesia sp), dentre outras, as informações são escassas.

No caso da pitangueira, algumas características particulares da espécie, além dos fatores já mencionados, levam a acreditar numa diferenciação populacional pelo aumento de endogamia decorrente da autofertilização. Esta hipótese é sustentada pelo padrão de floração da espécie, classificado como do tipo big-bang ou floração em massa (Lughadha \& Proença, 1996), que se caracteriza por apresentar grande produção de flores em curto espaço de tempo (Silva \& Pinheiro, 2007). Essa característica pode ser uma estratégia para atrair polinizadores $\left(\mathrm{O}^{\prime}\right.$ Brien \& Calder, 1993) e, em espécies autocompatíveis que necessitam da ação de polinizadores para maior frutificação, a floração em massa pode ser uma estratégia para promover a autofertilização (Beardsell et al., 1993), pois, além de atrair polinizadores, faz com que eles permaneçam mais tempo forrageando na mesma planta. A possibilidade de aumento de endogamia por autopolinização é levantada em outras espécies da família Myrtaceae, como em Myrtus communis, uma espécie típica da flora Mediterrânea (Agrimonti et al., 2007), e em Syzygium nervosum, espécie de polinização cruzada endêmica da Austrália (Shapcott, 1999).

Em relação ao modo de reprodução, os resultados evidenciam que E. uniflora é autocom- 
patível, embora Silva (2006) classifique a espécie como parcialmente autocompatível, com índice de autocompatibilidade igual a 0,62 , sendo consideradas autocompatíveis espécies com índice acima de 0,75 (Lloyd \& Schoen, 1992). Franzon (2008) também classifica a pitangueira como autocompatível, mas que necessita da atuação de agentes polinizadores, principalmente abelhas melíferas, para melhor frutificação. Por essas características, a produção de frutos nessa espécie pode ocorrer por geitonogamia, que é aquela em que ocorre polinização com a transferência de pólen entre flores da mesma planta, embora a produção de frutos por autopolinização passiva possa ocorrer (Silva., 2006). A geitonogamia pode ser um fator limitante em espécies com autocompatibilidade incompleta (Mahoro, 2003) e, de acordo com Sedgley e Smith (1989), mesmo em espécies autocompatíveis, é possível que exista competição entre pólen da própria flor e aquele oriundo de flores diferentes, podendo ocorrer maior sucesso na frutificação quando ocorre polinização cruzada.

Deste modo, estudos mais detalhados sobre sua biologia reprodutiva, bem como características anatômicas das flores, devem ser conduzidos para determinar como ocorre a polinização, dispersão do pólen e sementes, e estruturação de populações, a fim de determinar a melhor maneira de conservação genética da espécie. Também, o uso de marcadores genéticos codominantes pode fornecer maiores informações sobre os índices de polinização cruzada e de autopolinização, bem como melhores esclarecimentos sobre a estimativa do fluxo de genes, uma vez que o caráter dominante do AFLP impede que sejam diferenciados locos homozigotos dominantes de locos heterozigotos, subestimando, assim, a frequência dos alelos recessivos.

Para a preservação da espécie, a existência de diferenciação populacional, relatada em trabalhos anteriores encontrados na literatura, associada com a hipótese de que ocorra uma taxa de autofertilização considerável, indica que mais populações existentes nos fragmentos de mata original devem ser conservadas para assegurar variabilidade suficiente. Em relação ao Banco Ativo de Germoplasma de fruteiras nativas da Embrapa Clima Temperado, a maioria das plantas de pitangueira, existentes hoje, têm a mesma origem, e poucas plantas foram introduzidas de outras regiões de Mata Atlântica, como Paraná e Santa Catarina. Assim, tornam-se necessárias novas coletas e introdução de material. Essa coleta deveria ser feita em vários locais de várias regiões, a fim de aumentar e preservar grande variabilidade para o futuro, principalmente quando se pensa em desenvolver um programa de melhoramento genético.

TABELA 1 - Pares de primers utilizados no estudo da variabilidade em populações de pitangueira (Eugenia uniflora), número de locos AFLP amplificados, número $\left(\mathrm{N}^{\circ} \mathrm{P}\right)$ e percentagem $(\% \mathrm{P})$ de polimorfismo encontrada para cada grupo (Gp52 e Gp15), e No P e \% P total.

\begin{tabular}{cccccccccc}
\hline & \multicolumn{3}{c}{$\mathrm{Gp52}(\mathrm{n}=37)$} & \multicolumn{3}{c}{$\mathrm{Gp} 15(\mathrm{n}=37)$} & \multicolumn{3}{c}{ Total $(\mathrm{n}=74)$} \\
\cline { 2 - 10 } Par de primers* & $\mathrm{N}^{\mathrm{o}} \mathrm{de}$ & \multirow{2}{*}{$\mathrm{N}^{\mathrm{O}} \mathrm{P}$} & $\% \mathrm{P}$ & $\begin{array}{l}\mathrm{N}^{\mathrm{o}} \mathrm{de} \\
\text { locos }\end{array}$ & $\mathrm{N}^{\mathrm{o}} \mathrm{P}$ & $\% \mathrm{P}$ & $\begin{array}{l}\mathrm{N}^{\circ} \mathrm{de} \\
\text { locos }\end{array}$ & $\mathrm{N}^{\circ} \mathrm{P}$ & $\% \mathrm{P}$ \\
\hline $\mathrm{P} 1$ & 50 & 26 & $52,0 \%$ & 52 & 27 & $51,9 \%$ & 64 & 46 & $71,9 \%)$ \\
$\mathrm{P} 2$ & 61 & 21 & $34,4 \%$ & 56 & 18 & $32,1 \%$ & 65 & 31 & $47,7 \%$ \\
$\mathrm{P} 3$ & 42 & 17 & $40,5 \%$ & 43 & 26 & $60,5 \%$ & 49 & 37 & $75,5 \%$ \\
\hline Total & 153 & 64 & $41,8 \%$ & 151 & 71 & $47,0 \%$ & 178 & 114 & $64,0 \%$ \\
\hline
\end{tabular}

*(P1) Eco+ACA / Mse+CTT; (P2) Eco +AGC / Mse+CTT; (P3) Eco+AAC / Mse+CAG. 
TABELA 2 - Número total de locos, número de polimorfismos $\left(\mathrm{N}^{\mathrm{o}} \mathrm{P}\right)$ e percentagem de polimorfismo (\% P) para cada população (oriundas de autopolinização ou polinização livre), formadas a partir de sementes coletadas de duas plantas ("Pit 52" e "Pit 15)" de pitangueira (Eugenia uniflora), mantidas na Embrapa Clima Temperado, em Pelotas-RS.

\begin{tabular}{cccccc}
\hline \multirow{2}{*}{ Mãe } & Polinização & $\mathrm{N}^{\circ}$. indivíduos & $\begin{array}{c}\mathrm{N}^{\circ} \text {. de } \\
\text { locos }\end{array}$ & $\mathrm{N}^{\circ} \mathrm{P}$ & $\% \mathrm{P}$ \\
\hline \multirow{2}{*}{ Pit 52 } & Auto & 18 & 153 & 41 & $26,8 \%$ \\
& Livre & 18 & 153 & 58 & $37,9 \%$ \\
\hline \multirow{2}{*}{ Pit 15} & Auto & 18 & 151 & 56 & $37,1 \%$ \\
& Livre & 18 & 151 & 65 & $43,0 \%$ \\
\hline
\end{tabular}

TABELA 3 - Análise da variância molecular (AMOVA) em dois grupos (Gp52 e Gp15) de plantas de pitangueira (Eugenia uniflora). Cada grupo é formado por 36 indivíduos, divididos em duas populações. $\mathrm{GL}=$ graus de liberdade; $\mathrm{SQ}=$ soma dos quadrados; $\mathrm{QM}=$ quadrados médios.

\begin{tabular}{|c|c|c|c|c|c|c|}
\hline Grupo & Fonte de variação & GL & SQ & QM & Componente de variância & Total $(\%)$ \\
\hline \multirow{4}{*}{ Gp52 } & Entre populações & 1 & 32,028 & 32,028 & 1,3079 & $13,36 * *$ \\
\hline & Dentro de populações & 34 & 288,5 & 8,485 & 8,4853 & $86,64 * *$ \\
\hline & Total & 35 & 320,52 & 9,158 & 9,7932 & 100,0 \\
\hline & $\mathrm{F}_{\mathrm{st}}=0,1336^{* *}$ & & & & & \\
\hline \multirow{4}{*}{ Gp15 } & Entre populações & 1 & 21,889 & 21,889 & 0,6554 & $6,1 * *$ \\
\hline & Dentro de populações & 34 & 343,11 & 10,092 & 10,0915 & $93,9^{\text {ns }}$ \\
\hline & Total & 35 & 365,0 & 10,429 & 10,7469 & 100,0 \\
\hline & $\mathrm{F}_{\mathrm{st}}=0,061 * *$ & & & & & \\
\hline
\end{tabular}

TABELA 4 - Resumo da AMOVA: percentagem da variação total observada entre populações de pitangueira (Eugenia uniflora), oriundas de autopolinização e polinização livre, coletadas de duas plantasmãe mantidas na Embrapa Clima Temperado, em Pelotas-RS.

\begin{tabular}{c|cccc}
\hline Populações & 52 auto & 52 livre & 15 auto & 15 livre \\
\hline 52 auto & -- & $13,36^{* *}$ & $62,93^{* *}$ & $57,48^{* *}$ \\
52 livre & & -- & $59,23^{* *}$ & $53,52^{* *}$ \\
15 auto & & & -- & $6,10^{* *}$ \\
15 livre & & & & -- \\
\hline
\end{tabular}

** significativo ao nível de $1 \%$ de probabilidade de erro. 


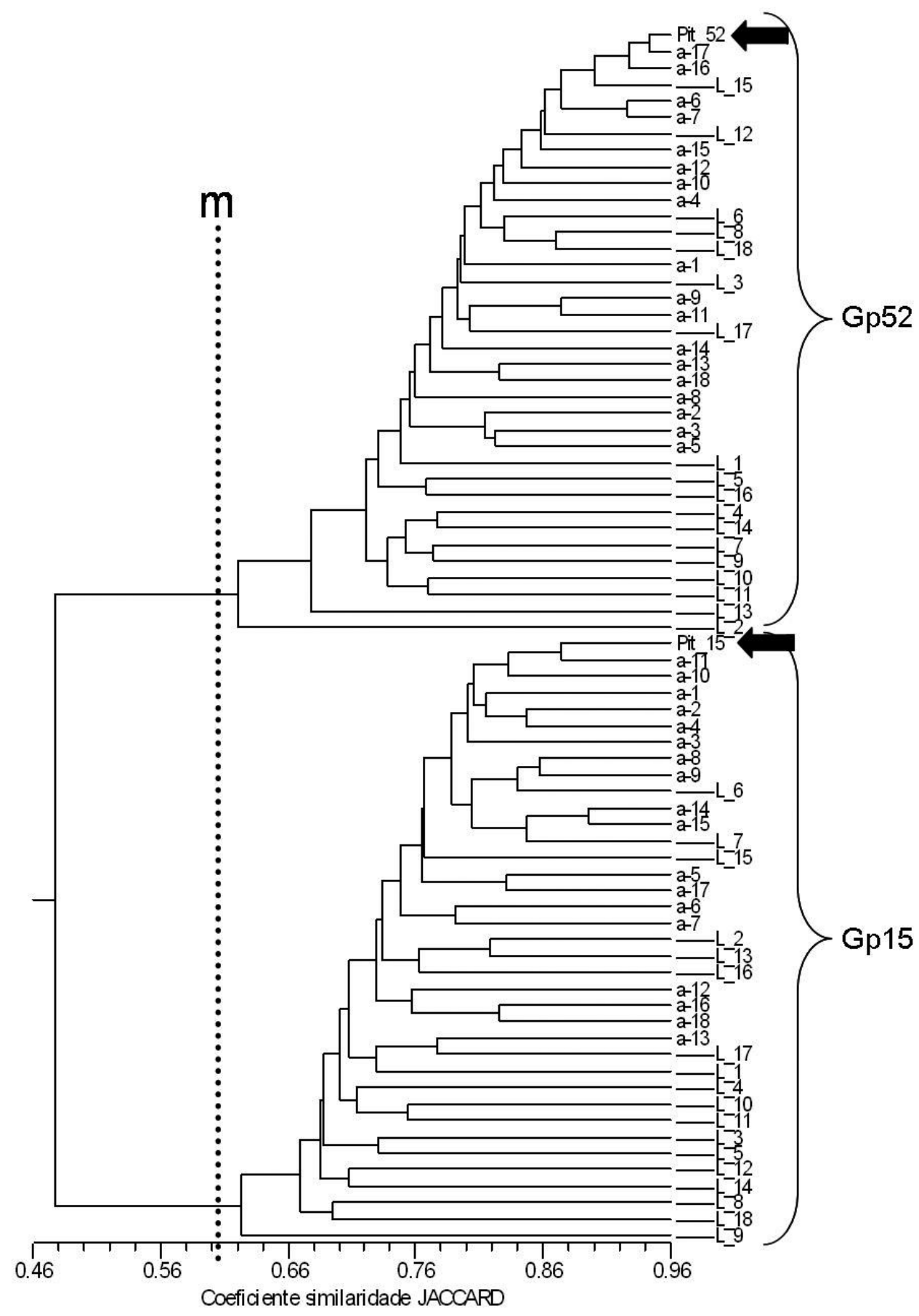

FIGURA 1 - Dendrograma representando a similaridade genética entre 74 plantas de pitangueira (Eugenia uniflora), a partir de 114 marcadores AFLP, com base no coeficiente de Jaccard, utilizando o método UPGMA. Coeficiente de correlação cofenética $(\mathrm{r}=0,96)$. Setas indicam as plantas-mãe (seleções "Pit 52" e "Pit 15"). (a) = indivíduo originado por autopolinização; (L) = indivíduo obtido por polinização livre; $(\mathrm{m})=$ similaridade média entre todos os indivíduos. 


\section{CONCLUSÕES}

Nas condições em que foi realizado o trabalho, conclui-se que:

1-Marcadores AFLP podem ser utilizados para o estudo da variabilidade genética entre e dentro de populações de E. uniflora.

2-Houve maior polimorfismo de marcadores AFLP em populações de polinização livre.

3-A proporção da variabilidade genética total entre populações foi significativa, embora tenha sido menor do que aquela observada dentro das populações.

4-A reprodução da pitangueira é decorrente tanto da autofertilização quanto da polinização cruzada, sendo necessários, no entanto, novos estudos para determinar qual a estratégia de reprodução mais eficiente.

\section{REFERÊNCIAS}

AGRIMONTI, C.; BIANCHI, R.; BIANCHI, A.; BALLERO, M.; POLI, F.; MARMIROLI, N. Understanding biological conservation strategies: a molecular-genetic approach it the case of myrtle (Myrtus communis L.) in two Italian regions: Sardinia and Calabria. Conservation Genetics, Heidelberg, v.8, n.2, p. 385-396, 2007.

ARADHYA, M.K.; WEEKS, C.; SIMON, C.J. Molecular characterization of variability and relationships among seven cultivated and selected wild species of Prunus L. using amplified fragment length polymorphism. Scientia Horticulturae, Amsterdam, v.103, n.1, p.131-144, 2004.

BEARDSELL, D.V.; O'BRIEN, S.P.; WILLIAMS, E.G.; KNOX, R.B.; CALDER, D.M. Reproductive biology of Australian Myrtaceae. Australian Journal of Botany, Collingwood, v.41, n.4-5, p.511-526, 1993.

BIANCHI, V.J.; FACHINELLO, J.C.; SCHUCH, M.W. RAPDs na caracterização genético-molecular e no estudo da variabilidade genética de cultivares de ameixeira. Revista Brasileira de Fruticultura, Jaboticabal, v.25, n.2, p.272-274, 2003.

BRETÓ, M.P.; RUIZ, C.; PINA, J.A.; ASINS, M.J. The Diversification of Citrus clementina Hort. ex Tan., a Vegetatively Propagated Crop Species. Molecular Phylogenetics and Evolution, Amsterdam, v.21, n.2, p.285-293, 2001
CERVERA, M.T.; CABEZAS, J.A.; SANCHA, J.C.; TODA, F.M.; ZAPATER, J.M.M. Application of AFLPs to the characterization of gravepine Vitis vinifera $\mathrm{L}$. genetic resources. A case study with accessions from Rioja (Spain). Theoretical and Applied Genetics, New York, v.97, n.1-2, p.51-59, 1998.

CRESTE, S.; TULMANN-NETO, A.; FIGUEIRA, A. Detection of single sequence repeat polymorphism in denaturing polyacrylamide sequencing gels by silver staining. Plant Molecular Biology Reporter, Georgia, v.19, n.4, p.299-306, 2001.

DETTORI, M.T.; PALOMBI, M.A. Identification of Feijoa sellowiana Berg accessions by RAPD markers. Scientia Horticulturae, Amsterdam, v.86, n.4, p.279-290, 2000.

DONADIO, L.C.; MÔRO, F.V.; SERVIDONE, A.A. Frutas brasileiras. Jaboticabal: Novos Talentos, 2002. 288p.

DOYLE, J.J.; DOYLE, J.L. Isolation of plant DNA from fresh tissue. Focus, Gaithesburg, v.12, p.13$15,1987$.

EXCOFFIER, L.; SMOUSE, P.; QUATTRO, J. Analysis of molecular variance inferred from metric distances among DNA haplotypes - application to human mitochondrial-DNA restriction data. Genetics, Maryland, v.131, n.2, p.479-491, 1992.

FERREIRA, M.E.; MORETZSOHN, M.C.; BUSO, G.S.C. Fundamentos de caracterização molecular de germoplasma vegetal. In: NASS, L.L. (Ed.). Recursos genéticos vegetais. Brasília: Embrapa Recursos Genéticos e Biotecnologia, 2007. p.377-420.

FRANZON, R.C. Propagação vegetativa e modo de reprodução da pitangueira (Eugenia uniflora L.). 2008. 100f. Tese (Doutorado em Agronomia - área de concentração em Fruticultura de Clima Temperado) - Faculdade de Agronomia Eliseu Maciel, Universidade Federal de Pelotas, Pelotas, 2008.

LLOYD, D.G.; SCHOEN, D. Self and crossfertilization in plants. I - Functional dimensions. Internacional Journal of Plant Sciences, Chicago, v.153, n.3, p.358-369, 1992.

LUGHADHA, E.N.; PROENÇA, C. A survey of the reproductive biology of the Myrtoideae (Myrtaceae). Annals of the Missouri Botanical Garden, St. Louis, v.83, n.4, p.480-503, 1996. 
MAHORO, S. Effects of flower and seed predators and pollinators on fruit production in two sequentially flowering congeners. Plant Ecology, Dordrecht, v.166, n.1, p.37-48, 2003.

MARGIS, R.; FELIX, D.; CALDAS, J.F.; SALGUEIRO, F.; ARAÚJO, D.S.D.; BREYNE, P.; VAN MONTAGU, M.; OLIVEIRA, D.DE; MARGISPINHEIRO, M. Genetic differentiation among three neighboring Brazil-cherry (Eugenia uniflora L.) populations within the Brazilian Atlantic rain forest. Biodiversity and Conservation, London, v.11, n.1, p.149-163, 2002.

MEHLENBACHER, S.A. Classical and molecular approaches to breeding fruit and nut crops for disease resistance. Hortscience, Alexandria, v.30, n.3, p.466-477, 1995.

MWASE, W.F.; BJORNSTAD, A.; STEDJE, B.; BOKOSI, J.M.; KWAPATA, M.B. Genetic diversity of Uapaca kirkiana Muel. Arg. populations as revealed by amplified fragment length polymorphisms (AFLPs). African Journal of Biotechnology, Nairobi, v5, n13, p.1205-1213, 2006.

O'BRIEN, S.P.; CALDER, D.M. Reproductivebiology and floral phenologies of the sympatric species Leptospermum myrsinoides and L. continentale (Myrtaceae). Australian Journal of Botany, Collingwood, v.41, n.4-5, p.527-539, 1993.

OUBORG, N.J.; PIQUOT, T.; GROENENDAEL, M.V. Population genetics, molecular markers and the study of dispersal in plants. Journal of Ecology, Durham, v.87, n.4, p.551-568, 1999.

PIGATO, S.M.P.C.; LOPES, C.R. Avaliação da variabilidade genética em quatro gerações de $E u$ calyptus urophylla S.T. Blake por meio de marcador molecular RAPD. Scientia Forestalis, Piracicaba, n.60, p.119-133, 2001.

PROENÇA, C.E.B.; GIBBS, P.E. Reproductive biology of eight sympatric Myrtaceae from Central Brazil. New Phytologist, Oxford, v.126, n.2, p.343354, 1994.

ROHLF, F. J. NTSYS-pc: numerical taxonomy and multivariate analysis system, version 2.1. New York: Exeter Software, 2000. 83p.
SALGUEIRO, F.; FELIX, D.; CALDAS, J.F.; MARGIS-PINHEIRO, M.; MARGIS, R. Even population differentiation for maternal and biparental gene markers in Eugenia uniflora, a widely distributed species from the Brazilian coastal Atlantic rain forest. Diversity and Distributions, Oxford, v.10, n.3, p.201-210, 2004.

SALLA, M.F.S.; RUAS, C.F.; RUAS, P.M.; CARPENTIERI-PÍPOLO, V. Uso de marcadores moleculares na análise da variabilidade genética em acerola (Malpighia emarginata D.C.). Revista Brasileira de Fruticultura, Jaboticabal, v.24, n.1, p.15-22, 2002.

SEDGLEY, M.; SMITH, R.M. Pistil receptivity and pollen tube growth in relation to the breeding system of Eucalyptus woodwardii (Symphyomyrtus: Myrtaceae). Annals of Botany, London, v.64, n.1, p.21-31, 1989.

SHAPCOTT, A. Vagility and the monsoon rain forest archipelago of northern Australia: patterns of genetic diversity in Syzigium nervosum (Myrtaceae). Biotropica, Washington, v.31, n.4, p.579-590, 1999.

SILVA, A.L.G. Biologia reprodutiva de quatro espécies de Eugenia L. (Myrtaceae). 2006. 99f. Tese (Doutorado em Ciências Biológicas)- Universidade Federal do Rio de Janeiro, Rio de Janeiro. 2006.

SILVA, A.L.G.; PINHEIRO, M.C.B. Biologia floral e da polinização de quatro espécies de Eugenia L. (Myrtaceae). Acta Botanica Brasilica, Brasília, v.21, n.1, p.235-247, 2007.

SOKAL, R.R.; ROHLF, F.J. The comparison of dendrograms by objective methods. Taxon, Berlin, v.11, n.1, p.30-40, 1962.

UPADHYAY, A.; JAYADEV, K.; MANIMEKALAI, R.; PARTHASARATHY, V.A. Genetic relationship and diversity in Indian coconut accessions based on RAPD markers. Scientia Horticulturae, Amsterdam, v.99, n.3-4, p.353-362, 2004.

VIANA, A.P.; PEREIRA, T.N.S.; PEREIRA, M.G.; SOUZA, M.M.; MALDONADO, J.F.M.; JÚNIOR, A.T.A. Diversidade genética entre genótipos comerciais de maracujazeiro-amarelo (Passiflora edulis f. flavicarpa) e entre espécies de passifloras nativas determinada por marcadores RAPD. Revista Brasileira de Fruticultura, Jaboticabal, v.25, n.3, p.489-493, 2003. 
VIEIRA, E.A.; NODARI, R.O.; DANTAS, A.C.M.; DUCROQUET, J.P.H.J.; DALBÓ, M.; BORGES, C.V. Genetic mapping of Japanese plum. Crop Breeding and Applied Biotechnology, Londrina, v.5, n.1, p.29-37, 2005.

VOS, P.; HOGERS, R.; BLEEKER, M.; REIJANS, M.; LEE, T.V.; HORNES, M.; FRIJTERS, A.; POT, J.; PELEMAN, J.; KULPER, M.; ZABEAU, M. AFLP: a new technique for DNA fingerprinting. Nucleic Acids Research, London, v.23, n.21, p.4407-4414, 1995.
WANG, X.L.; CHIANG, T.Y.; ROUX, N.; HAO, G.; GE, X.J. Genetic diversity of wild banana (Musa balbisiana Colla) in China as revealed by AFLP markers. Genetic Resources and Crop Evolution, Dordrecht, v.54, n.5, p.1125-1132, 2007.

YAMAGISHI, M.; SHIGEHITO, M.; NAKATSUKA, A.; ITAMURA, H. Identification of persimmon (Diospyros kaki) cultivars and phenetic relationships between Dyospyros species by more effective RAPD analysis. Scientia Horticulturae, Amsterdam, v.105, n.2, p.283-290, 2005. 